\title{
One-year sustained efficacy of erenumab in episodic migraine
}

\author{
Results of the STRIVE study
}

Peter J. Goadsby, MD, PhD, Uwe Reuter, MD, PhD, Yngve Hallström, MD, Gregor Broessner, MD, PhD, Jo H. Bonner, MD, Feng Zhang, MS, Ian K. Wright, PhD, Denise E. Chou, MD, Jan Klatt, MD, Hernan Picard, MD, PhD, Robert A. Lenz, MD, PhD, and Daniel D. Mikol, MD, PhD

Neurology ${ }^{\circledR}$ 2020;95:e469-e479. doi:10.1212/WNL.0000000000010019

\section{Abstract}

\section{Objective}

To assess efficacy and tolerability of 1-year erenumab treatment in patients with episodic migraine.

\section{Methods}

Patients were randomized $(\mathrm{n}=955 ; 1: 1: 1)$ during the 24-week double-blind treatment phase (DBTP) to monthly subcutaneous placebo or erenumab 70 or $140 \mathrm{mg}$. At week 24,845 patients were rerandomized $(1: 1)$ to erenumab 70 or $140 \mathrm{mg}$ during the 28 -week dose-blinded activetreatment phase (ATP). Monthly migraine days (MMD), achieving $\geq 50 \%, \geq 75 \%$, and $100 \%$ reduction in MMD, and safety/tolerability were assessed.

\section{Results}

Mean MMD at DBTP baseline was 8.3. At week 52, mean changes (SE) from pre-DBTP baseline/ week 24 (pre-ATP baseline) in MMD were -4.2 (0.2)/-1.1 (0.2) (70 mg) and -4.6 (0.2)/-1.8 (0.2) $(140 \mathrm{mg})$ irrespective of treatment during the DBTP. For patients reducing dose from 140 (DBTP) to $70 \mathrm{mg}$ (ATP), change in MMD from week 24 to 52 was $-0.1(0.3)$, and for those increasing from 70 (DBTP) to $140 \mathrm{mg}$ (ATP), -1.8 (0.3). At week 52, 61.0\%, 38.5\%, and $19.8 \%$ of patients on erenumab $70 \mathrm{mg}$, and $64.9 \%, 40.8 \%$, and $21.2 \%$ on erenumab $140 \mathrm{mg}$, achieved $\geq 50 \%, \geq 75 \%$, and $100 \%$ reduction in MMD from DBTP baseline, respectively. Among erenumab-treated patients in DBTP who showed $\geq 50 \%$ reduction in MMD during the last 3 months of DBTP and completed ATP, $86 \%$ showed sustained responses at $\geq 50 \%$ during the last 3 months of ATP. Safety of erenumab in ATP was similar to DBTP; exposure-adjusted incidence rates of adverse events were similar for either dose.

\section{Conclusion}

Over 52 weeks, erenumab provided sustained efficacy in episodic migraine; the safety profiles were similar between erenumab dose groups in the presence of dose blinding.

\section{Clinicaltrials.gov identifier \\ NCT02456740.}

\section{Classification of evidence}

Class II evidence that 52 weeks of treatment with erenumab 70 and 140 mg subcutaneously monthly results in sustained reductions in monthly migraine days and similar dose tolerability for patients with episodic migraine.

\author{
Correspondence \\ Dr. Goadsby \\ peter.goadsby@kcl.ac.uk
}

\section{MORE ONLINE}

$\rightarrow$ Class of Evidence

Criteria for rating therapeutic and diagnostic studies

NPub.org/coe 


\section{Glossary}

ATP = active treatment phase; CGRP = calcitonin gene-related peptide; DBTP = double-blind treatment phase; FAS = full analysis set; ICHD-3b = International Classification of Headache Disorders, edition 3 beta; $\mathbf{M M D}=$ monthly migraine day; MPFID-EA = Migraine Physical Function Impact Diary everyday activities; MPFID-PI = Migraine Physical Function Impact Diary physical impairment; PRO = patient-reported outcome; SE = standard error; STRIVE = Study to Evaluate the Efficacy and Safety of Erenumab in Migraine Prevention; TEAE = treatment-emergent adverse event.

Adherence to available standard of care preventive therapies for episodic migraine is poor, with patients citing insufficient efficacy or poor tolerability as the most common reasons for discontinuation. ${ }^{1,2}$ Hence, there is a high unmet need for new preventive therapies that provide sustained efficacy and good tolerability to enable longer-term adherence and reduce the impact of migraine on patients' lives.

The calcitonin gene-related peptide (CGRP) pathway plays an important role in migraine pathophysiology. ${ }^{3}$ Erenumab (in the United States, erenumab-aooe), a fully human monoclonal antibody that selectively targets and blocks the canonical CGRP receptor, ${ }^{4}$ was recently approved in several countries as a monthly subcutaneous injection of 70 or $140 \mathrm{mg}$ for the prevention of migraine in adults. Several studies have demonstrated the clinical efficacy of erenumab 70 and $140 \mathrm{mg}$ across the migraine spectrum, ${ }^{5-9}$ including STRIVE (Study to Evaluate the Efficacy and Safety of Erenumab in Migraine Prevention), which included erenumab $70 \mathrm{mg}$ and $140 \mathrm{mg}$ vs placebo in patients with episodic migraine over a 24-week double-blind treatment phase (DBTP). ${ }^{6}$

For any new drug and mechanism of action, it is important to provide longer-term safety data and evidence for sustained efficacy beyond that observed during the relatively short placebocontrolled study period. Ashina et al. ${ }^{10}$ reported 1-year interim safety and efficacy analyses of erenumab $70 \mathrm{mg}$ from a 5-year open-label extension of a phase 2 episodic migraine trial. Here, we report the results of the 28-week dose-blinded active treatment phase (ATP) of the STRIVE study, which followed the 24-week DBTP, to assess the efficacy, tolerability, and safety of erenumab 70 and $140 \mathrm{mg}$ over a 1-year period.

\section{Methods}

\section{Primary research question}

Does erenumab treatment in patients with episodic migraine result in sustained reduction in monthly migraine days (MMDs) and improvement in patient-reported outcomes over a 1-year period?

\section{Standard protocol approvals, registrations, and patient consents}

This trial is registered with ClinicalTrials.gov (NCT 02456740). The trial protocol was approved by the independent ethics committee at each trial center. All patients provided written informed consent. Amgen and Novartis funded this study.

\section{Study design}

STRIVE was a phase 3, multicenter, randomized, doubleblind, placebo-controlled, parallel-group study of patients with episodic migraine. ${ }^{6}$ During the 24-week DBTP, patients were randomized (1:1:1) to receive placebo or erenumab 70 or $140 \mathrm{mg}$ monthly, administered subcutaneously. Patients who completed the DBTP entered a 28-week ATP, where they were rerandomized to receive either erenumab $70 \mathrm{mg}$ or erenumab $140 \mathrm{mg}$ once monthly in a dose-blinded fashion. Rerandomization was stratified as per the treatment groups (placebo, erenumab $70 \mathrm{mg}$, or erenumab $140 \mathrm{mg}$ ) assigned during the DBTP (figure 1). The primary approach to analyze long-term efficacy in this study was to evaluate outcomes in 2 groups: patients who received erenumab $70 \mathrm{mg}$ during the ATP and patients who received erenumab $140 \mathrm{mg}$ during the ATP, irrespective of treatment received during the DBTP. Hereafter, these groups will be referred to as all erenumab $70 \mathrm{mg}$ and all erenumab $140 \mathrm{mg}$. Given that the study design includes 2 randomizations, at the study baseline (pre-DBTP baseline) and at week 24 (pre-ATP baseline), efficacy results are presented in 2 ways: change from the pre-DBTP (study) baseline and change from the pre-ATP baseline. In these analyses, the pre-DBTP (study) baseline refers to the monthly measurement obtained during the baseline period before the first dose of erenumab or placebo in the DBTP. The pre-ATP baseline refers to the last monthly measurement obtained at the end of the DBTP (in most cases at week 24, before the first dose of erenumab in the ATP). Change from the pre-ATP baseline was the primary analytical approach for the ATP as this was when rerandomization occurred. A safety follow-up was performed 16 weeks after the last dose of erenumab in ATP, e.g., at week 64 for patients receiving the final dose of erenumab at week 48 .

\section{Participants}

Eligibility criteria for enrollment into the STRIVE study have been reported previously. ${ }^{7}$ Briefly, the key inclusion criteria were being aged 18-65 years with a history of episodic migraine with or without aura based on the International Classification of Headache Disorders, edition 3 beta (ICHD-3b), ${ }^{11}$ for $\geq 12$ months before screening, having 4-14 migraine days per month and $<15$ headache days per month across the 3 months prior to screening and during the 1-month pre-DBTP baseline period. Anxiety and depression as comorbidities were permitted in the trial. Patients were excluded if they had no therapeutic response (defined as no improvement in frequency, severity, or duration of migraines after $\geq 6$ weeks of treatment at the appropriate dose) to $>2$ migraine preventive medication categories or had 




The active treatment phase (ATP) treatment group was stratified by double-blind treatment phase (DBTP) treatment assignment. All erenumab 70 mg in the ATP comprised patients with the following DBTP treatment assignments: placebo $(n=138)$, erenumab $70 \mathrm{mg}(n=140)$, erenumab 140 mg $(n=143)$. All erenumab $140 \mathrm{mg}$ in the ATP comprised patients with the following DBTP treatment assignments: placebo $(n=140)$, erenumab 70 mg $(n=140)$, erenumab $140 \mathrm{mg}(\mathrm{n}=144)$. Pre-DBTP (study) baseline: the monthly measurement obtained before the first dose of erenumab or placebo in the DBTP: pre-ATP baseline: the last monthly measurement obtained at the end of the DBTP (in most cases at week 24 before the first dose of erenumab in the ATP). QM = once monthly; SC = subcutaneous; STRIVE = Study to Evaluate the Efficacy and Safety of Erenumab in Migraine Prevention.

medication overuse according to ICHD-3b criteria. ${ }^{11}$ To be eligible to enter the ATP, patients were required to complete the DBTP, not discontinue erenumab early, continue to provide informed consent, and be considered appropriate by the investigators for treatment continuation or initiation.

\section{Outcomes}

We report analyses of the ATP of the STRIVE study, which aimed to assess the efficacy, tolerability, and safety of erenumab through 52 weeks and to assess the effect of switching doses. Efficacy endpoints studied during the ATP included change from baseline in MMD and acute MSMD through week 52, and achievement of a $\geq 50 \%, \geq 75 \%$, or $100 \%$ reduction in MMD from baseline to week 52 .

Endpoints for patient-reported outcomes (PROs) included change from baseline in Migraine Physical Function Impact Diary physical impairment (MPFID-PI) and everyday activities 
(MPFID-EA) domains through week 52. The MPFID is a 13item PRO instrument used daily, which measures the impact of migraine on physical functioning. ${ }^{12}$ For each domain, the scores range from 0 to 100 , with higher scores representing greater impact with migraine (i.e., higher burden).

The overall safety and tolerability of erenumab was also assessed. Safety endpoints included all adverse events, clinical laboratory values, vital signs, electrocardiograms, and testing for antierenumab antibodies. Treatment-emergent adverse events (TEAEs) were coded using the Medical Dictionary for Regulatory Activities, version 20.0, and graded according to severity based on the Common Terminology Criteria for Adverse Events (CTCAE) system, version 4.03. (The adverse events in DBTP primary analysis were coded in MedDRA 19.1; in ATP, the preferred terms were coded in MedDRA v20.0. The preferred term nasopharyngitis in MedDRA 19.1 was coded to viral upper respiratory tract infection in MedDRA v20.0.)

\section{Statistical analyses}

The ATP full analysis set (FAS) consisted of all patients receiving at least one dose of erenumab during the ATP. Patients were analyzed according to their randomized treatment in both DBTP and ATP. The FAS was used in analyses of baseline characteristics, disposition, efficacy endpoints, and PROs during the ATP. The ATP safety analysis set consisted of all patients receiving at least one dose of erenumab during the ATP. This analysis set was used for summarizing safety data and erenumab exposure during the ATP. Patients in this safety analysis set were analyzed according to their rerandomized treatment unless a patient had received the incorrect dose (i.e., $70 \mathrm{mg}$ instead of $140 \mathrm{mg}$, or vice versa) during the entire ATP. In this case, patients who received the incorrect dose were analyzed in the dose group of the actual dose received.

Comparison between the active treatment groups was based on descriptive statistics and no statistical testing comparing the active treatment groups was performed. Data were reported as mean and SD or standard error, and as first and third quartiles and minimum and maximum for the continuous efficacy endpoints (MMD, acute MSMD, and MPFID); for the dichotomous efficacy endpoints $(\geq 50 \%, \geq 75 \%$, and $100 \%$ responses in MMD reduction), frequency and percentages were reported. For efficacy (MMD and acute MSMD) and PRO endpoints (MPFID-PI and MPFID-EA), change at week 52 was calculated from the pre-DBTP (study) baseline and preATP baseline (week 24), respectively, and the $\geq 50 \%, \geq 75 \%$, and $100 \%$ responses were calculated based on change in MMD from the pre-DBTP (study) baseline. Safety and tolerability were assessed throughout the ATP and adverse events are reported as exposure-adjusted subject incidence rate per 100 subject-years.

\section{Data availability}

The data for the STRIVE ATP analyses described in this article are available by request from author investigators, Amgen Inc., or Novartis Pharma AG.

\section{Results}

\section{Patient disposition}

Of 955 patients who were enrolled in the DBTP of the STRIVE study, 845 (88.5\%) entered the ATP and were rerandomized to receive blinded treatment with either erenumab $70 \mathrm{mg}(\mathrm{n}=$ 421; all erenumab $70 \mathrm{mg}$ group) or erenumab $140 \mathrm{mg}$ ( $\mathrm{n}=$ 424; all erenumab $140 \mathrm{mg}$ group). Of the 845 patients entering the ATP, $84.4 \%$ were women, $90.2 \%$ were white, and the mean (SD) age at the study baseline was 41.6 (11.1) years (table 1). Baseline characteristics of patients entering the ATP were consistent with those of patients enrolled in the DBTP. All 845 patients who entered the ATP received at least one dose of erenumab and were included in the ATP FAS as well as the ATP safety analysis set. The ATP was completed by 762 of 845 (90.2\%) patients (i.e., completed the assessment at week 52); discontinuations from the ATP were for the following reasons: subject request $(n=55[6.5 \%])$, lost to follow-up $(n=17$ $[2.0 \%])$, protocol-specified criteria $(n=10[1.2 \%])$, and death $(\mathrm{n}=1[0.1 \%])$ (figure 1$)$. Two patients received incorrect dose during the ATP and were flagged as important protocol deviation.

\section{Efficacy results}

The all erenumab $70 \mathrm{mg}$ and all erenumab $140 \mathrm{mg}$ groups included patients from each of the 3 DBTP groups (placebo, erenumab $70 \mathrm{mg}$, and erenumab $140 \mathrm{mg}$ ); hence, the results of the change from the pre-ATP (week 24) baseline reflect a combined treatment effect in patients from each of these 3 groups over weeks 24 through 52. The mean (standard error [SE]) change in MMD from the pre-DBTP (study) baseline and pre-ATP baseline based on dose received during the ATP is presented in figure 2. The mean (SE) change in MMD during the ATP (i.e., from the pre-ATP baseline to week 52) was -1.1 $(0.2)$ and $-1.8(0.2)$ days in the all erenumab $70 \mathrm{mg}$ and all erenumab $140 \mathrm{mg}$ groups, respectively (figure $2 \mathrm{C}$ ), whereas the mean (SE) change from the pre-DBTP (study) baseline to week 52 was $-4.2(0.2)$ and $-4.6(0.2)$ days, respectively (figure 2B).

Results for change in MMD over time for the overall study population (figure 2A) showed that the efficacy of erenumab was sustained over the 52 weeks for both 70 and $140 \mathrm{mg}$. Similar results were seen when analyzing the data just for those patients who completed the ATP, and in both cases negative slopes were observed, suggesting some further reduction in MMD during the ATP (figure e-1, doi.org/10.5061/dryad. 63xsj3v0n).

In addition to analyzing the treatment effect on $\mathrm{MMD}$ in the all erenumab $70 \mathrm{mg}$ and all erenumab $140 \mathrm{mg}$ groups, analyses for change in MMD from the pre-ATP baseline were conducted in pairs, as follows: (1) patients either continuing the $70 \mathrm{mg}$ dose $(-1.1[0.4])$ or increasing the dose from 70 to $140 \mathrm{mg}(-1.8$ [0.3]) during the ATP; (2) patients either continuing the $140 \mathrm{mg}(-0.6[0.3])$ dose or decreasing the dose to $70 \mathrm{mg}$ $(-0.1[0.3])$ during the ATP; (3) patients treated with placebo 
Table 1 Demographics and characteristics at study baseline (double-blind treatment phase) of patients entering the active treatment phase (ATP)

\begin{tabular}{|c|c|c|c|}
\hline & $\begin{array}{l}\text { All erenumab } 70 \mathrm{mg} \\
(\text { ATP })(\mathrm{N}=421)\end{array}$ & $\begin{array}{l}\text { All erenumab } 140 \mathrm{mg} \\
\text { (ATP) }(\mathrm{N}=424)\end{array}$ & Total $(\mathrm{N}=845)$ \\
\hline Age, y & $41.3(11.3)$ & $41.9(10.9)$ & $41.6(11.1)$ \\
\hline Women & $354(84.1)$ & $359(84.7)$ & $713(84.4)$ \\
\hline Race, white & $382(90.7)$ & $380(89.6)$ & $762(90.2)$ \\
\hline \multicolumn{4}{|l|}{ Treatment with migraine preventive medication } \\
\hline Naive & $238(56.5)$ & $230(54.2)$ & $468(55.4)$ \\
\hline Prior or current use & $168(39.9)$ & $185(43.6)$ & $353(41.8)$ \\
\hline Current use & $15(3.6)$ & $9(2.1)$ & $24(2.8)$ \\
\hline \multicolumn{4}{|l|}{ Baseline disease characteristics } \\
\hline MMD & $8.3(2.5)$ & $8.2(2.4)$ & $8.3(2.5)$ \\
\hline Acute migraine-specific medication use & $266(63.2)$ & $255(60.1)$ & $521(61.7)$ \\
\hline Monthly acute migraine-specific medication days & $3.6(3.4)$ & $3.5(3.5)$ & $3.6(3.5)$ \\
\hline MPFID-EA (range) & $13.5(0-50.2)$ & $13.3(0-49.4)$ & $13.4(0-50.2)$ \\
\hline MPFID-PI (range) & $12.1(0-62.2)$ & $12.1(0-50.2)$ & $12.1(0-62.2)$ \\
\hline
\end{tabular}

Abbreviations: $\mathrm{MMD}=$ monthly migraine day; MPFID-EA = Migraine Physical Function Impact Diary everyday activities; MPFID-PI = Migraine Physical Function Impact Diary physical impairment; $\mathrm{N}=$ number of patients who received at least one erenumab dose in the ATP; $\mathrm{n}=$ number of patients with nonmissing values; $\%=\mathrm{n} / \mathrm{N} * 100$.

Data are mean (SD) or $\mathrm{n}(\%)$. For MPFID-EA and MPFID-PI, domain score ranges from 0 to 100 with higher scores representing greater impact of migraine (i.e., higher burden).

during the DBTP and switching to either $70 \mathrm{mg}(-2.2[0.4])$ or $140 \mathrm{mg}(-2.9[0.4])$ during the ATP. These analyses show that efficacy was maintained for both erenumab doses during the ATP, with numerically greater efficacy observed for erenumab 140 vs $70 \mathrm{mg}$.

In the ATP, the mean (SE) change in the monthly acute MSMD from the pre-ATP baseline to week 52 was -0.7 (0.1) days in the all erenumab $70 \mathrm{mg}$ group and $-1.0(0.1)$ days in the all erenumab $140 \mathrm{mg}$ group (table 2). Between baseline and week 52, the mean (SE) change was -1.8 (0.1) days and -2.0 (0.2) days in the all erenumab $70 \mathrm{mg}$ group and the all erenumab $140 \mathrm{mg}$ group.

The effect of erenumab on patient-reported physical function and everyday activities was determined using the MPFID. As shown in table 2, the mean (SE) change during ATP in monthly average MPFID-PI score from the pre-ATP baseline to week 52 was $-1.3(0.4)$ in the all erenumab $70 \mathrm{mg}$ group and $-1.9(0.3)$ in the all erenumab $140 \mathrm{mg}$ group, where negative change reflects improvement; the mean (SE) change in MPFID-EA score was $-1.8(0.4)$ in the all erenumab $70 \mathrm{mg}$ group and -2.3 (0.4) in the all erenumab $140 \mathrm{mg}$ group during the ATP.

In terms of response to treatment at week 52 , the proportions of patients who achieved $\geq 50 \%, \geq 75 \%$, and $100 \%$ reduction in MMD from the study baseline were $61.0 \%, 38.5 \%$, and $19.8 \%$ in the all erenumab $70 \mathrm{mg}$ group, and $64.9 \%, 40.8 \%$, and $21.2 \%$ in the all erenumab $140 \mathrm{mg}$ group, respectively (table 2; figure 3 ). Further analysis was done to assess extent to which patients exhibit a sustained response to erenumab treatment. Among patients receiving erenumab during the DBTP who completed 52 weeks' treatment and achieved $\geq 50 \%$ reduction in $\mathrm{MMD}$ from study baseline over the last 3 months of the DBTP, $86.0 \%$ and $86.8 \%$ of patients in the all erenumab $70 \mathrm{mg}$ and all erenumab $140 \mathrm{mg}$ groups, respectively, sustained this $\geq 50 \%$ reduction in MMD during the last 3 months of the ATP (table 3 ). Among erenumab-treated patients who completed 52 weeks' of treatment but did not achieve $\geq 50 \%$ reduction in $\mathrm{MMD}$ over the last 3 months of the DBTP, $31.6 \%$ of patients in the all erenumab $70 \mathrm{mg}$ group and $38.9 \%$ in the all erenumab $140 \mathrm{mg}$ group achieved $\geq 50 \%$ reduction in MMD during the last 3 months of the ATP (table 3). In those patients receiving placebo during the DBTP and initiating erenumab during the ATP, 58.0\% (70 mg: 52.1\%; $140 \mathrm{mg}: 63.9 \%$ ) achieved $\geq 50 \%$ reduction in MMD during the last 3 months of the ATP.

\section{Safety and tolerability}

Overall, TEAEs during the ATP were reported in 241 (57.2\%) and $233(55.0 \%)$ patients in the all erenumab $70 \mathrm{mg}$ and the all erenumab $140 \mathrm{mg}$ groups, respectively (table 4 ). The exposureadjusted subject incidence rates were 134.6 per 100 subjectyears in the all erenumab $70 \mathrm{mg}$ group and 122.0 per 100 subject-years the all erenumab $140 \mathrm{mg}$ group (table 4). These findings were lower than the exposure-adjusted subject incidence rates for TEAEs for patients receiving either placebo 
Figure 2 Mean change in monthly migraine days (MMDs) from pre-double-blind treatment phase (DBTP) and pre-active treatment phase (ATP) baselines

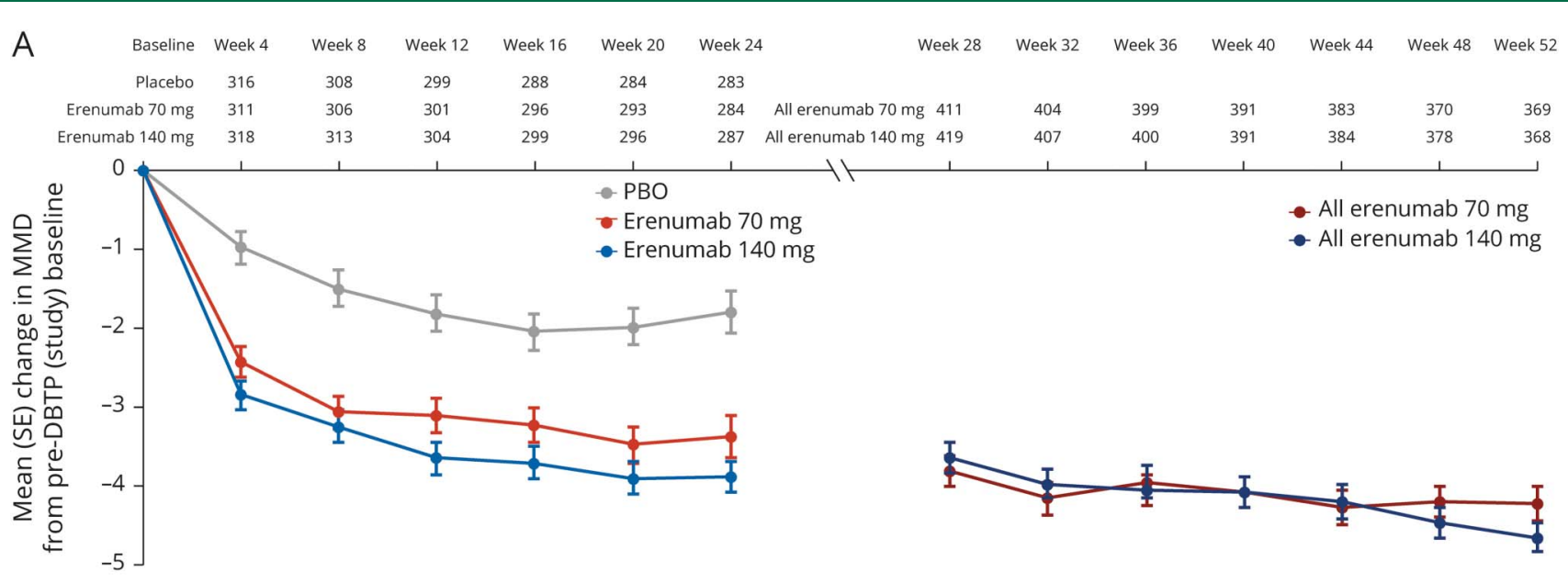

B. Pre-DBTP (study) baseline to week 52



C. Pre-ATP baseline (week 24) to week 52

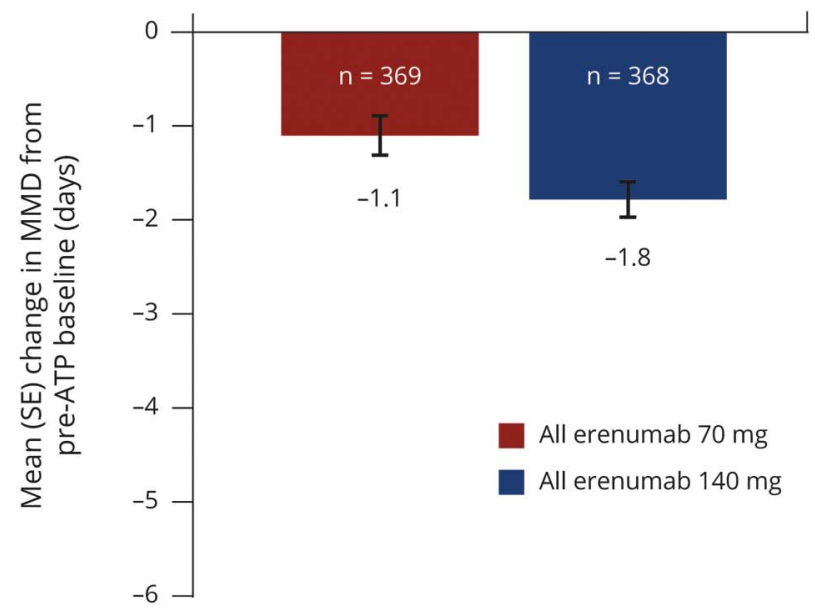

Mean change (SE) in MMDs from the (A) pre-DBTP baseline every 4 weeks during weeks 0-52; (B) pre-DBTP (study) baseline at week 52; and (C) pre-ATP baseline at week 52. MMDs = monthly migraine days; PBO = placebo; SE = standard error.

(256.2 per 100 subject-years) or erenumab $70 \mathrm{mg}(215.0$ per 100 subject-years) or $140 \mathrm{mg}$ (208.5 per 100 subject-years) during the DBTP. TEAEs in the ATP with the highest exposure-adjusted incidence rates were viral upper respiratory tract infection (the preferred term nasopharyngitis in MedDRA 19.1 was coded to viral upper respiratory tract infection in MedDRA v20.0) and upper respiratory tract infection (table 5 ); incidence rates of events during longer-term treatment with erenumab were not increased compared with rates observed during the DBTP (table 6).

TEAEs with a severity grade $\geq 3$ occurred in $6.2 \%$ ( 8.8 per 100 subject-years) of patients in the all erenumab $70 \mathrm{mg}$ group and in $4.7 \%$ (6.6 per 100 subject-years) of patients in the all erenumab 140 mg group; grade $\geq 4$ TEAEs were reported in 3 patients in the all erenumab $140 \mathrm{mg}$ group (1.0 per 100 subject-years) (table 4).
Adverse events leading to discontinuation of treatment in the ATP were low and occurred in 6 patients $(2.0$ per 100 subjectyears) in the all erenumab $70 \mathrm{mg}$ group (monocytopenia, idiopathic orbital inflammation, swollen tongue, injection site pain, migraine [ 2 cases]), and in 10 patients ( 3.2 per 100 subjectyears) in the all erenumab $140 \mathrm{mg}$ group (monocytopenia, arrhythmogenic right ventricular dysplasia, fatigue, subdural hematoma, increased alanine aminotransferase, breast fibroma, migraine, anxiety, dyspnea, papular rash, and urticaria).

Serious TEAEs were reported for 14 patients each in the all erenumab $70 \mathrm{mg}$ and all erenumab $140 \mathrm{mg}$ groups, with corresponding exposure-adjusted subject incidence rates of 4.7 and 4.5 per 100 subject-years, respectively.

There were no clinically significant changes observed in vital signs and laboratory values in either treatment group during the ATP. 
Table 2 Baseline values and change from baseline in outcome measures during the active treatment phase (ATP)

\begin{tabular}{|c|c|c|c|c|}
\hline Outcome & $\mathbf{N}$ & $\begin{array}{l}\text { All erenumab } 70 \mathrm{mg} \\
(\text { ATP })(\mathrm{N}=421)\end{array}$ & $\mathbf{N}$ & $\begin{array}{l}\text { All erenumab } 140 \mathrm{mg} \\
(\text { ATP })(\mathrm{N}=424)\end{array}$ \\
\hline \multicolumn{5}{|l|}{ MMD } \\
\hline Pre-DBTP baseline, mean (SD) & 419 & $8.3(2.5)$ & 424 & $8.2(2.4)$ \\
\hline Change from pre-DBTP baseline to week 52 , mean (SE) & 369 & $-4.2(0.2)$ & 368 & $-4.6(0.2)$ \\
\hline Pre-ATP baseline, mean (SD) & 419 & $5.2(4.1)$ & 424 & $5.3(4.4)$ \\
\hline Change from pre-ATP baseline to week 52 (ATP), mean (SE) & 369 & $-1.1(0.2)$ & 368 & $-1.8(0.2)$ \\
\hline $\begin{array}{l}\text { Proportion of patients achieving } \geq 50 \% \text { reduction in MMD } \\
\text { from pre-DBTP baseline at Week } 52, n(\%)\end{array}$ & 369 & $225(61.0)$ & 368 & $239(64.9)$ \\
\hline \multicolumn{5}{|l|}{ Acute MSMD ${ }^{a}$} \\
\hline Pre-DBTP baseline, mean (SD) & 419 & $3.6(3.4)$ & 424 & $3.5(3.5)$ \\
\hline Change from pre-DBTP baseline to week 52 , mean (SE) & 369 & $-1.8(0.1)$ & 368 & $-2.0(0.2)$ \\
\hline Pre-ATP baseline, mean (SD) & 419 & $2.6(3.5)$ & 424 & $2.5(3.5)$ \\
\hline Change from pre-ATP baseline to week 52 , mean (SE) & 369 & $-0.7(0.1)$ & 368 & $-1.0(0.1)$ \\
\hline \multicolumn{5}{|l|}{ MPFID-PI } \\
\hline Pre-DBTP baseline, mean (SD) & 419 & $12.1(9.3)$ & 424 & $12.1(9.1)$ \\
\hline Change from pre-DBTP baseline to week 52 , mean (SE) & 368 & $-5.4(0.5)$ & 368 & $-5.7(0.5)$ \\
\hline Pre-ATP baseline, mean (SD) & 419 & $8.2(10.8)$ & 424 & $8.1(9.8)$ \\
\hline Change from pre-ATP baseline to week 52, mean (SE) & 368 & $-1.3(0.4)$ & 368 & $-1.9(0.3)$ \\
\hline \multicolumn{5}{|l|}{ MPFID-EA } \\
\hline Pre-DBTP baseline, mean (SD) & 419 & $13.5(8.6)$ & 424 & $13.3(8.6)$ \\
\hline Change from pre-DBTP baseline to week 52 , mean (SE) & 368 & $-6.9(0.5)$ & 368 & $-7.1(0.4)$ \\
\hline Pre-ATP baseline, mean (SD) & 419 & $8.4(10.3)$ & 424 & $8.3(9.5)$ \\
\hline Change from pre-ATP baseline to week 52 , mean (SE) & 368 & $-1.8(0.4)$ & 368 & $-2.3(0.4)$ \\
\hline
\end{tabular}

Abbreviations: DBTP = double-blind treatment phase; MMD = monthly migraine day; MPFID-EA = Migraine Physical Function Impact Diary everyday activities; MPFID-PI = Migraine Physical Function Impact Diary physical impairment; MSMD = migraine-specific medication day .

${ }^{a}$ As only $\sim 60 \%$ of patients were taking acute migraine-specific medications during the pre-DBTP baseline, the effect shown here for the overall population is less than that observed in patients using migraine-specific medications during the pre-DBTP baseline.

One death was reported during the ATP in the all erenumab $140 \mathrm{mg}$ group. The patient was a 44-year-old man with a medical history of abnormal electrocardiograms (first-degree atrioventricular block, intraventricular conduction defects, and inverted T waves), insufficiency of the mitral valve, hypercholesterolemia, and hypertriglyceridemia. The patient, who switched from erenumab $70 \mathrm{mg}$ in the DBTP to $140 \mathrm{mg}$ in the ATP, was asymptomatic and did not report any adverse events. The reported cause of death was heart failure. Postmortem assessment included genetic testing, which revealed that the patient had a genetic variant of arrhythmogenic right ventricular dysplasia, a condition associated with sudden cardiac death. ${ }^{13,14}$ The event was deemed not related to erenumab by the investigator.

Of the 842 patients who received erenumab during the ATP and who had a postbaseline positive antibody assessment after the first dose of erenumab during the ATP, 28 (3.3\%) developed antierenumab binding (non-neutralizing) antibodies on at least one occasion, and 12 of these 28 patients had a negative antidrug antibody result at the last time point tested. No patient developed antierenumab neutralizing antibodies during the ATP.

\section{Discussion}

Erenumab at either 70 or $140 \mathrm{mg}$ resulted in a sustained reduction in MMD of over $50 \%$ from the DBTP (study) baseline to week 52, with sustained efficacy observed over weeks 24-52. Similarly, both doses of erenumab also resulted in a reduction of over $50 \%$ from DBTP baseline to week 52 in the number of days using acute migraine-specific medications per month. In addition, the double-blind dosing of the ATP phase demonstrated no difference in tolerability, as reflected in exposure-adjusted subject incidence rates of adverse events, between 70 and $140 \mathrm{mg}$ of erenumab. 
Table 3 Proportion of patients completing 52 weeks of erenumab treatment who achieved $\geq 50 \%$ reduction in monthly migraine days (MMDs) during the last 3 months of the active treatment phase (ATP) categorized by treatment response during the last 3 months of the double-blind treatment phase (DBTP)

\begin{tabular}{|c|c|c|c|c|c|c|c|}
\hline & \multicolumn{2}{|l|}{ DBTP $70 \mathrm{mg}$} & \multicolumn{3}{|c|}{ DBTP $140 \mathrm{mg}$} & \multicolumn{2}{|l|}{ ATP } \\
\hline & ATP $70 \mathrm{mg}$ & ATP $140 \mathrm{mg}$ & ATP $70 \mathrm{mg}$ & ATP $140 \mathrm{mg}$ & Total & $70 \mathrm{mg}$ & $140 \mathrm{mg}$ \\
\hline \multicolumn{8}{|c|}{$\begin{array}{l}\text { Achieved } \geq 50 \% \text { reduction in MMDs during } \\
\text { the last } 3 \text { months of the DBTP }\end{array}$} \\
\hline N1 & 66 & 54 & 70 & 67 & 257 & 136 & 121 \\
\hline Sustained responders, $\mathrm{n}(\%)$ & $61(92.4)$ & $45(83.3)$ & $56(80.0)$ & $60(89.6)$ & $222(86.4)$ & $117(86.0)$ & $105(86.8)$ \\
\hline \multicolumn{8}{|c|}{$\begin{array}{l}\text { Did not achieve } \geq 50 \% \text { reduction in MMDs } \\
\text { during the last } 3 \text { months of the DBTP }\end{array}$} \\
\hline N1 & 56 & 72 & 58 & 59 & 245 & 114 & 131 \\
\hline Delayed responders, n (\%) & $18(32.1)$ & $31(43.1)$ & $18(31.0)$ & 20 (33.9) & $87(35.5)$ & 36 (31.6) & $51(38.9)$ \\
\hline
\end{tabular}

Abbreviation: N1 = number of patients completing 52-week erenumab treatment with available MMD response.

Sustained responders include patients who achieved $\geq 50 \%$ reduction in MMD during the last 3 months of the DBTP and the last 3 months of the ATP. Delayed responders include patients who did not achieve $\geq 50 \%$ reduction in MMDs during the last 3 months of the DBTP but achieved during the last 3 months of the ATP.

In clinical practice, assessing response to treatment is helpful in decision-making and is often defined as achievement of $\geq 50 \%$ reduction from baseline in MMD. In clinical trials, different thresholds of response are commonly employed to understand the spectrum of response to treatment. ${ }^{15}$ Longterm treatment with erenumab resulted in substantial proportions of patients with sustained responses over the last 3 months of the ATP, which were broadly similar in both arms. The percentages of patients achieving $\geq 50 \%$ response at week 52 were higher than those for erenumab 70 and $140 \mathrm{mg}$ in the DBTP, ${ }^{6}$ suggesting that response to treatment may be greater with longer-term treatment, although to some extent there is a natural history and responder consideration in these data. ${ }^{16}$ It is noteworthy that a large proportion of patients (86\%) who responded $(\geq 50 \%)$ at the end of the DBTP continued to respond during the $\mathrm{ATP}$, and $36 \%$ of patients who did not respond during the DBTP did respond in the ATP.
We measured the impact of migraine on patients' physical functioning over the 28-week ATP using the MPFID ${ }^{12}$ and found that both doses of erenumab resulted in reductions (i.e., improvement) in MPFID scores on the everyday activity and physical impairment domains. This improvement in MPFID domain scores is likely to be due, at least in part, to the reduction in MMD, but it is also possible that other factors may have contributed, such as reduced severity of migraine headaches.

In the DBTP of the STRIVE study, both erenumab $70 \mathrm{mg}$ and erenumab $140 \mathrm{mg}$ consistently produced a greater reduction in MMD compared with placebo. ${ }^{6}$ This benefit extended into the ATP where (1) patients switching from placebo to erenumab 140 or $70 \mathrm{mg}$, (2) patients who increased dose from 70 to $140 \mathrm{mg}$ compared with those who remained on $70 \mathrm{mg}$ throughout the study, and (3) patients treated with $140 \mathrm{mg}$

Figure 3 Proportion of patients achieving $\geq 50 \%, \geq 75 \%$, and $100 \%$ reduction in monthly migraine days (MMDs) from pre-double-blind treatment phase (DBTP) baseline

A

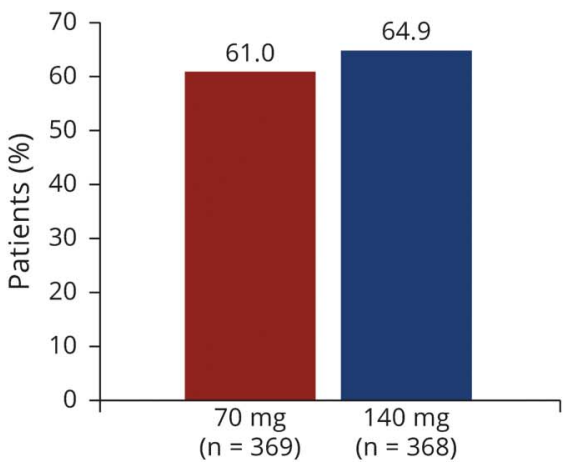

B

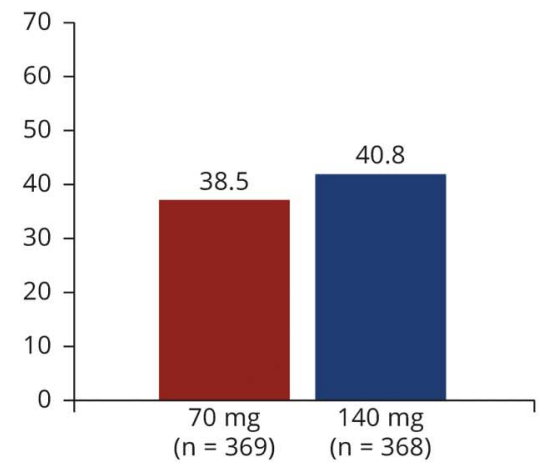

C

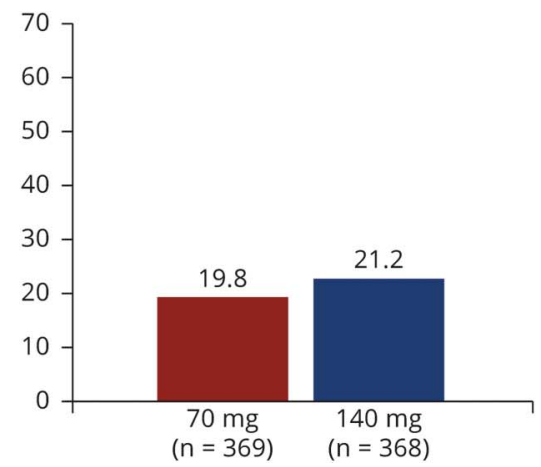

Proportion of patients achieving (A) $\geq 50 \%$; $(B) \geq 75 \%$; and (C) $100 \%$ reduction in MMDs from the pre-DBTP (study) baseline to week 52 . 
Table 4 Adverse events reported during the active treatment phase (ATP)

\begin{tabular}{|c|c|c|}
\hline & All erenumab $70 \mathrm{mg}(\mathrm{N}=421), \mathrm{n}(\%) / \mathrm{e}(\mathrm{r})$ & All erenumab $140 \mathrm{mg}(\mathrm{N}=424), n(\%) / \mathrm{e}(r)$ \\
\hline All TEAEs & $241(57.2) / 179.1(134.6)$ & $233(55.0) / 190.9(122.0)$ \\
\hline \multicolumn{3}{|l|}{ Severity } \\
\hline Grade $\geq 2$ & $162(38.5) / 230.3(70.4)$ & $147(34.7) / 240.9(61.0)$ \\
\hline Grade $\geq 3$ & $26(6.2) / 295.4(8.8)$ & $20(4.7) / 303.5(6.6)$ \\
\hline Grade $\geq 4$ & 0 & $3(0.7) / 310.5(1.0)$ \\
\hline Serious adverse events & $14(3.3) / 299.7(4.7)$ & $14(3.3) / 307.8(4.5)$ \\
\hline Adverse events leading to discontinuation & $6(1.4) / 304.9(2.0)$ & $10(2.4) / 308.7(3.2)$ \\
\hline Fatal adverse events & 0 & $1(0.2)^{a / 311.3(0.3)}$ \\
\hline \multicolumn{3}{|c|}{$\begin{array}{l}\text { Abbreviations: } \mathrm{e}=\text { sum across all patients, the total time at risk in the ATP in years (time from the first dose of erenumab during the ATP through the earliest of } \\
\text { the first event onset date in the ATP, end of study date, or last erenumab dose date in the ATP }+112 \text { days); } N=\text { number of patients who received at least one } \\
\text { erenumab dose in the ATP; } n=\text { number of patients reporting at least one occurrence of an adverse event; } \%=n / N \times 100 ; r=\text { exposure-adjusted subject } \\
\text { incidence rate per } 100 \text { subject-years }(n / e \times 100) \text {; TEAEs }=\text { treatment-emergent adverse events. } \\
\text { a One patient who switched from erenumab } 70 \mathrm{mg} \text { in the double-blind treatment phase to erenumab } 140 \mathrm{mg} \text { in the ATP died of arrhythmogenic right } \\
\text { ventricular dysplasia. A postmortem assessment that included genetic testing revealed the patient was heterozygous for a frameshift variant consistent with } \\
\text { a genetic form of arrhythmia/cardiomyopathy. }\end{array}$} \\
\hline
\end{tabular}

throughout the study compared with those who decreased dose from 140 to $70 \mathrm{mg}$ all continued to maintain effects, which were not different.
Given the downward slope for change in MMD over weeks 24-52, we questioned whether this might reflect attrition bias, i.e., dropout of patients not responding well to

Table 5 Exposure-adjusted incidence rates of treatment-emergent adverse events (TEAEs) (occurring at a rate of $\geq 2$ subjects per 100 subject-years in the total group) during the active treatment phase (ATP) by preferred term

\begin{tabular}{|c|c|c|}
\hline & All erenumab $70 \mathrm{mg}(\mathrm{N}=421), \mathrm{n}(\%) / \mathrm{e}(\mathrm{r})$ & All erenumab $140 \mathrm{mg}(\mathrm{N}=424), \mathrm{n}(\%) / \mathrm{e}(\mathrm{r})$ \\
\hline All TEAES & $241(57.2) / 179.1(134.6)$ & $233(55.0) / 190.9(122.0)$ \\
\hline Viral upper respiratory tract infection & $58(13.8) / 282.9(20.5)$ & $44(10.4) / 293.3(15.0)$ \\
\hline Upper respiratory tract infection & $25(5.9) / 293.9(8.5)$ & $19(4.5) / 303.0(6.3)$ \\
\hline Nausea & $12(2.9) / 299.7(4.0)$ & $11(2.6) / 305.9(3.6)$ \\
\hline Urinary tract infection & $15(3.6) / 300.5(5.0)$ & $7(1.7) / 307.7(2.3)$ \\
\hline Influenza & $13(3.1) / 304.5(4.3)$ & $9(2.1) / 307.1(2.9)$ \\
\hline Sinusitis & $6(1.4) / 305.3(2.0)$ & $15(3.5) / 305.3(4.9)$ \\
\hline Arthralgia & $13(3.1) / 299.3(4.3)$ & $7(1.7) / 307.8(2.3)$ \\
\hline Migraine & $11(2.6) / 303.0(3.6)$ & $9(2.1) / 306.6(2.9)$ \\
\hline Diarrhea & $11(2.6) / 302.1(3.6)$ & $8(1.9) / 307.6(2.6)$ \\
\hline Fatigue & $6(1.4) / 303.1(2.0)$ & $11(2.6) / 305.7(3.6)$ \\
\hline Bronchitis & $10(2.4) / 304.1(3.3)$ & $7(1.7) / 307.9(2.3)$ \\
\hline Back pain & $7(1.7) / 302.9(2.3)$ & $8(1.9) / 309.0(2.6)$ \\
\hline Dizziness & $8(1.9) / 302.4(2.6)$ & $6(1.4) / 307.7(2.0)$ \\
\hline Influenza-like illness & $7(1.7) / 304.0(2.3)$ & $7(1.7) / 307.7(2.3)$ \\
\hline Gastroenteritis & $8(1.9) / 304.6(2.6)$ & $3(0.7) / 310.3(1.0)$ \\
\hline Constipation & $6(1.4) / 303.9(2.0)$ & $4(0.9) / 309.3(1.3)$ \\
\hline
\end{tabular}

Abbreviations: $\mathrm{e}=$ sum across all patients, the total time at risk in the ATP in years (time from the first dose of erenumab during the ATP through the earliest of the first event onset date in the ATP, end of study date, or last erenumab dose date in the ATP +112 days); $N=$ number of patients who received at least one erenumab dose in the ATP; $n=$ number of patients reporting at least one occurrence of an adverse event in that class; $\%=n / N \times 100 ; r=$ exposure-adjusted subject incidence rate per 100 subject-years $(\mathrm{n} / \mathrm{e} \times 100)$.

Preferred terms were coded in MedDRA v20.0. The preferred term nasopharyngitis in MedDRA 19.1 was coded to viral upper respiratory tract infection in MedDRA v20.0. 
Table 6 Exposure-adjusted subject incidence rates of treatment-emergent adverse events (TEAEs) (occurring at a rate of $\geq 5$ subjects per 100 subject-years in any group) during the double-blind treatment phase (DBTP) by preferred term

\begin{tabular}{llll}
\hline & Placebo $(\mathbf{N}=\mathbf{3 1 9}), \mathbf{n}(\%) / \mathbf{e}(\mathbf{r})$ & Erenumab 70 $\mathbf{~ g}(\mathbf{N}=\mathbf{3 1 4}), \mathbf{n}(\%) / \mathbf{e}(\mathbf{r})$ & Erenumab 140 mg $(\mathbf{N}=\mathbf{3 1 9}), \mathbf{n}(\%) / \mathbf{e}(\mathbf{r})$ \\
\hline All TEAEs & $201(63.0) / 78.5(256.2)$ & $180(57.3) / 83.7(215.0)$ & $177(55.5) / 84.9[208.5]$ \\
\hline Nasopharyngitis & $32(10.0) / 131.9(24.9)$ & $31(9.9) / 133.4(23.2)$ & $35(11.0) / 133.6(26.2)$ \\
\hline $\begin{array}{l}\text { Upper respiratory tract } \\
\text { infection }\end{array}$ & $18(5.6) / 138.1(13.0)$ & $21(6.7) / 138.8(15.1)$ & $15(4.7) / 140.5(10.7)$ \\
\hline Sinusitis & $7(2.2) / 141.1(5.0)$ & $7(2.2) / 142.8(4.9)$ & $11(3.4) / 140.9(7.8)$ \\
\hline Constipation & $4(1.3) / 141.2(2.8)$ & $5(1.6) / 141.9(3.5)$ & $11(3.4) / 140.6(7.8)$ \\
\hline Fatigue & $8(2.5) / 140.1(5.7)$ & $6(1.9) / 142.3(4.2)$ & $7(2.2) / 141.5(4.9)$ \\
\hline Back pain & $7(2.2) / 140.5(5.0)$ & $6(1.9) / 142.3(4.2)$ & $6(1.9) / 142.4(4.2)$ \\
\hline Urinary tract infection & $7(2.2) / 140.3(5.0)$ & $5(1.6) / 143.0(3.5)$ & $7(2.2) / 142.4(4.9)$ \\
\hline Influenza & $6(1.9) / 140.8(4.3)$ & $4(1.3) / 143.2(2.8)$ & $8(2.5) / 142.3(5.6)$ \\
\hline Injection site pain & $1(0.3) / 142.0(0.7)$ & $10(3.2) / 140.7(7.1)$ & $1(0.3) / 143.7(0.7)$ \\
\hline Migraine & $10(3.1) / 139.3(7.2)$ & $4(1.3) / 142.9(2.8)$ & $3(0.9) / 143.9(2.1)$ \\
\hline Hypertension & $8(2.5) / 140.1(5.7)$ & $5(1.6) / 143.1(3.5)$ & 0 \\
\hline
\end{tabular}

Abbreviations: ATP = active treatment phase; e = sum across all patients, the total time at risk in the DBTP in years (time from the first dose of investigational product during the DBTP through the earliest of the first event onset date in the DBTP, the end of study date, or last dose date in DBTP); $N=$ number of patients in the analysis set; $n=$ number of patients reporting at least one occurrence of an adverse event; $\%=n / N \times 100 ; r=$ exposure-adjusted subject incidence rate per 100 subject-years $(\mathrm{n} / \mathrm{e} \times 100)$.

Preferred terms were coded in MedDRA v19.1.

treatment. However, there was a low dropout rate $(9.8 \%)$ in the ATP and, moreover, when only assessing patients who completed the ATP, a similar negative slope was observed, suggesting that efficacy might be somewhat greater at the end of the ATP, although this study was neither designed nor powered to address the possibility of increasing efficacy over time.

Long-term efficacy of erenumab $(70 \mathrm{mg})$ has also been demonstrated in a separate open-label extension study in episodic migraine (NCT01952574), ${ }^{9}$ which had comparable outcomes. Thus, sustained efficacy has been seen in both the STRIVE ATP and a separate phase 2 open-label extension ${ }^{9}$; in addition, both studies displayed high retention rates.

Erenumab had a favorable safety and tolerability profile during the ATP and the overall incidence rate of TEAEs was comparable with that observed in the $\mathrm{DBTP}^{6}$ and other erenumab migraine prevention studies. ${ }^{5,89}$ No new safety signals were reported during the ATP and, importantly, no dosedependent adverse events were observed. The blinded nature of the ATP allows for strong conclusions around adverse events, which clinicians could use when discussing treatment choice with patients. The most common events observed during the ATP (viral upper respiratory tract infection and upper respiratory tract infection) were also observed during the DBTP of this study. ${ }^{6}$ During the DBTP, the incidence of antierenumab binding antibodies was low, ${ }^{6}$ and this remained low throughout the ATP; no patients developed transient neutralizing antibodies during the ATP.

Discontinuation rates due to adverse events were low during the 28-week ATP. The result is in agreement with that reported in the 1-year open-label extension study of erenumab $70 \mathrm{mg}$ in episodic migraine (2.5\%). ${ }^{9}$ These findings are relevant because longer-term adherence with current migraine therapies is low, mainly because of tolerability and safety concerns. ${ }^{1,17}$ For example, Hepp et al. ${ }^{18}$ reported that the overall persistence with oral migraine preventive medication is poor at 6 months $(25 \%)$ and declines further at 12 months (14\%). The sustained treatment benefits and good tolerability observed with erenumab may thus lead to improved long-term treatment adherence and outcomes, although this requires confirmation.

These data show that the efficacy of erenumab in both dose groups in patients with episodic migraine is sustained through 1 year of treatment, with a favorable safety and tolerability profile.

\section{Acknowledgment}

The study was funded by Amgen Inc. The authors thank the study investigators and patients for their participation and commitment to this work.

\section{Study funding}

The study was funded by Amgen Inc. Erenumab is codeveloped by Amgen and Novartis. 


\section{Disclosure}

The study was funded by Amgen Inc. Erenumab is codeveloped by Amgen and Novartis. P.J. Goadsby received grants and personal fees from Amgen and Eli Lilly and Company; personal fees from Alder Biopharmaceuticals, Allergan, Autonomic Technologies Inc., ElectroCore, eNeura, MundiPharma, Novartis, Teva, WL Gore, and Trigemina Inc. (stock options); personal fees from MedicoLegal work, Upto-Date, Oxford University Press, Massachusetts Medical Society, and Wolters Kluwer; and owns a patent on magnetic stimulation for headache assigned to eNeura without fee. U. Reuter received consulting fees, speaking/teaching fees, and/ or research grants from Allergan, Amgen, Autonomic Technologies, CoLucid, ElectroCore, Novartis, Medscape, Eli Lilly, StreaMedup, and Teva. Y. Hallström served on the advisory board for Amgen, Novartis, and Sanofi. G. Broessner received consulting fees from Novartis, Pfizer, Allergan, Teva, Grünenthal, and Reckitt Benkiser; and served on the speakers' bureau for Novartis, Pfizer, Allergan, Menarini Pharm, Teva, Reckitt Benkiser, Eli Lilly, and Linde AG. He received research grants from Novartis and Amgen. J.H. Bonner reports no disclosures relevant to the manuscript. F. Zhang is an employee of and owns stock in Amgen. D.E. Chou is an employee of and owns stock in Amgen. J. Klatt is an employee of and owns stock in Novartis. H. Picard is an employee of and owns stock in Amgen. R.A. Lenz is an employee of and owns stock in Amgen. D.D. Mikol is an employee of and owns stock in Amgen. Go to Neurology.org/N for full disclosures.

\section{Publication history}

Received by Neurology August 1, 2019. Accepted in final form June 1, 2020.

\section{Appendix Authors}

\begin{tabular}{|c|c|c|}
\hline Name & Location & Contribution \\
\hline $\begin{array}{l}\text { Peter J. } \\
\text { Goadsby, } \\
\text { MD, PhD }\end{array}$ & $\begin{array}{l}\text { NIHR-Wellcome Trust King's } \\
\text { Clinical Research Facility, } \\
\text { King's College Hospital, } \\
\text { London, UK }\end{array}$ & $\begin{array}{l}\text { Interpretation of data, } \\
\text { intellectual content and } \\
\text { input into the manuscript }\end{array}$ \\
\hline $\begin{array}{l}\text { Uwe } \\
\text { Reuter, } \\
\text { MD, PhD }\end{array}$ & $\begin{array}{l}\text { Department of Neurology, } \\
\text { Charité } \\
\text { Universitätsmedizin Berlin, } \\
\text { Germany }\end{array}$ & $\begin{array}{l}\text { Acquisition of data, } \\
\text { interpretation of data, } \\
\text { intellectual content and } \\
\text { input into the manuscript }\end{array}$ \\
\hline $\begin{array}{l}\text { Yngve } \\
\text { Hallström, } \\
\text { MD }\end{array}$ & $\begin{array}{l}\text { Neuro Center, St Görans } \\
\text { Hospital, Stockholm, } \\
\text { Sweden }\end{array}$ & $\begin{array}{l}\text { Acquisition of data, } \\
\text { interpretation of data, } \\
\text { intellectual content and } \\
\text { input into the manuscript }\end{array}$ \\
\hline $\begin{array}{l}\text { Gregor } \\
\text { Broessner, } \\
\text { MD, PhD }\end{array}$ & $\begin{array}{l}\text { Department of Neurology, } \\
\text { Headache Outpatient } \\
\text { Clinic, Medical University of } \\
\text { Innsbruck, Austria }\end{array}$ & $\begin{array}{l}\text { Acquisition of data, } \\
\text { interpretation of data, } \\
\text { intellectual content and } \\
\text { input into the manuscript }\end{array}$ \\
\hline $\begin{array}{l}\text { Jo H. } \\
\text { Bonner, } \\
\text { MD }\end{array}$ & $\begin{array}{l}\text { Mercy Research, Saint } \\
\text { Louis, MO }\end{array}$ & $\begin{array}{l}\text { Acquisition of data, } \\
\text { interpretation of data, } \\
\text { intellectual content and } \\
\text { input into the manuscript }\end{array}$ \\
\hline $\begin{array}{l}\text { Feng } \\
\text { Zhang, MS }\end{array}$ & $\begin{array}{l}\text { Amgen Inc., Thousand } \\
\text { Oaks, CA }\end{array}$ & $\begin{array}{l}\text { Analysis of data, intellectual } \\
\text { content and input into the } \\
\text { manuscript }\end{array}$ \\
\hline
\end{tabular}

Appendix (continued)

\begin{tabular}{|c|c|c|}
\hline Name & Location & Contribution \\
\hline $\begin{array}{l}\text { lan K. } \\
\text { Wright, } \\
\text { PhD }\end{array}$ & $\begin{array}{l}\text { Novartis Irl Ltd, Dublin, } \\
\text { Ireland }\end{array}$ & $\begin{array}{l}\text { Medical writing support for } \\
\text { drafting and revision of } \\
\text { manuscript }\end{array}$ \\
\hline $\begin{array}{l}\text { Denise E. } \\
\text { Chou, MD }\end{array}$ & $\begin{array}{l}\text { Amgen Inc., Thousand } \\
\text { Oaks, CA }\end{array}$ & $\begin{array}{l}\text { Interpretation of data, } \\
\text { intellectual content and } \\
\text { input into the } \\
\text { manuscript }\end{array}$ \\
\hline $\begin{array}{l}\text { Jan Klatt, } \\
\text { MD }\end{array}$ & $\begin{array}{l}\text { Novartis Pharma AG, Basel, } \\
\text { Switzerland }\end{array}$ & $\begin{array}{l}\text { Interpretation of data, } \\
\text { intellectual content and } \\
\text { input into the } \\
\text { manuscript }\end{array}$ \\
\hline $\begin{array}{l}\text { Hernan } \\
\text { Picard, MD, } \\
\text { PhD }\end{array}$ & $\begin{array}{l}\text { Amgen Inc., Thousand } \\
\text { Oaks, CA }\end{array}$ & $\begin{array}{l}\text { Interpretation of data, } \\
\text { intellectual content and } \\
\text { input into the manuscript }\end{array}$ \\
\hline $\begin{array}{l}\text { Robert A. } \\
\text { Lenz, MD, } \\
\text { PhD }\end{array}$ & $\begin{array}{l}\text { Amgen Inc., Thousand } \\
\text { Oaks, CA }\end{array}$ & $\begin{array}{l}\text { Concept and study design, } \\
\text { interpretation of data, } \\
\text { intellectual content and } \\
\text { input into the manuscript }\end{array}$ \\
\hline $\begin{array}{l}\text { Daniel D. } \\
\text { Mikol, MD, } \\
\text { PhD }\end{array}$ & $\begin{array}{l}\text { Amgen Inc., Thousand } \\
\text { Oaks, CA }\end{array}$ & $\begin{array}{l}\text { Interpretation of data, } \\
\text { intellectual content and } \\
\text { input into the manuscript }\end{array}$ \\
\hline
\end{tabular}

\section{References}

1. Hepp Z, Bloudek LM, Varon SF. Systematic review of migraine prophylaxis adherence and persistence. J Manag Care Pharm 2014;20:22-33.

2. Woolley JM, Bonafede MM, Maiese BA, Lenz RA. Migraine prophylaxis and acute treatment patterns among commercially insured patients in the United States. Headache 2017;57:1399-1408.

3. Ho TW, Edvinsson L, Goadsby PJ. CGRP and its receptors provide new insights into migraine pathophysiology. Nat Rev Neurol 2010;6:573-582.

4. Shi L, Lehto S, Zhu DX, et al. Pharmacological characterization of AMG 334, a potent and selective human monoclonal antibody against the calcitonin gene-related peptide receptor. J Pharmacol Exp Ther 2016;356:223-231.

5. Dodick DW, Ashina M, Brandes JL, et al. ARISE: a phase 3 randomized trial of erenumab for episodic migraine. Cephalalgia 2018;38:1026-1037.

6. Goadsby PJ, Reuter U, Hallstrom Y, et al. A controlled trial of erenumab for episodic migraine. N Engl J Med 2017;377:2123-2132.

7. Tepper SJ, Ashina M, Reuter U, et al. A phase 2, randomised, double-blind, placebocontrolled study to evaluate the efficacy and safety of erenumab in chronic migraine prevention. Lancet Neurol 2017;16:425-434.

8. Sun H, Dodick DW, Silberstein S, et al. Safety and efficacy of AMG 334 for prevention of episodic migraine: a randomised, double-blind, placebo-controlled, phase 2 trial. Lancet Neurol 2016;15:382-390.

9. Reuter U, Goadsby PJ, Lanteri-Minet M, et al. Efficacy and tolerability of erenumab in patients with episodic migraine in whom two-to-four previous preventive treatments were unsuccessful: a randomised, double-blind, placebo-controlled, phase $3 \mathrm{~b}$ study. Lancet 2018;392:2280-2287.

10. Ashina M, Dodick D, Goadsby PJ, et al. Erenumab (AMG 334) in episodic migraine: interim analysis of an ongoing open-label study. Neurology 2017;89:1237-1243.

11. Headache Classification Committee of the International Headache Society (IHS). The International Classification of Headache Disorders, 3rd edition (beta version). Cephalalgia 2013;33:629-808.

12. Kawata AK, Hsieh R, Bender R, et al. Psychometric evaluation of a novel instrument assessing the impact of migraine on physical functioning: the migraine physical function impact diary. Headache 2017;57:1385-1398.

13. Corrado D, Link MS, Calkins H. Arrhythmogenic right ventricular cardiomyopathy. N Engl J Med 2017;376:61-72.

14. Orgeron GM, Calkins H. Advances in the diagnosis and management of arrhythmogenic right ventricular dysplasia/cardiomyopathy. Curr Cardiol Rep 2016;18:53.

15. Silberstein S, Tfelt-Hansen P, Dodick DW, et al. Guidelines for controlled trials of prophylactic treatment of chronic migraine in adults. Cephalalgia 2008;28:484-495.

16. Serrano D, Lipton RB, Scher AI, et al. Fluctuations in episodic and chronic migraine status over the course of 1 year: implications for diagnosis, treatment and clinical trial design. J Headache Pain 2017;18:101.

17. Vécsei L, Majláth Z, Szok D, Csáti A, Tajti J. Drug safety and tolerability in prophylactic migraine treatment. Expert Opin Drug Saf 2015;14:667-681.

18. Hepp Z, Dodick DW, Varon SF, et al. Persistence and switching patterns of oral migraine prophylactic medications among patients with chronic migraine: a retrospective claims analysis. Cephalalgia 2017;37:470-485. 


\section{Neurology}

\section{One-year sustained efficacy of erenumab in episodic migraine: Results of the STRIVE study}

Peter J. Goadsby, Uwe Reuter, Yngve Hallström, et al.

Neurology 2020;95;e469-e479 Published Online before print July 7, 2020

DOI 10.1212/WNL.0000000000010019

\section{This information is current as of July 7, 2020}

\section{Updated Information \& Services}

References

Citations

Subspecialty Collections

Permissions \& Licensing

Reprints including high resolution figures, can be found at: http://n.neurology.org/content/95/5/e469.full

This article cites 18 articles, 2 of which you can access for free at: http://n.neurology.org/content/95/5/e469.full\#ref-list-1

This article has been cited by 1 HighWire-hosted articles: http://n.neurology.org/content/95/5/e469.full\#\#otherarticles

This article, along with others on similar topics, appears in the following collection(s):

\section{All Clinical trials}

http://n.neurology.org/cgi/collection/all_clinical_trials

Class II

http://n.neurology.org/cgi/collection/class_ii

Migraine

http://n.neurology.org/cgi/collection/migraine

Information about reproducing this article in parts (figures,tables) or in its entirety can be found online at:

http://www.neurology.org/about/about_the_journal\#permissions

Information about ordering reprints can be found online:

http://n.neurology.org/subscribers/advertise

Neurology ${ }^{\circledR}$ is the official journal of the American Academy of Neurology. Published continuously since 1951, it is now a weekly with 48 issues per year. Copyright Copyright (C) 2020 The Author(s). Published by Wolters Kluwer Health, Inc. on behalf of the American Academy of Neurology.. All rights reserved. Print ISSN: 0028-3878. Online ISSN: 1526-632X.

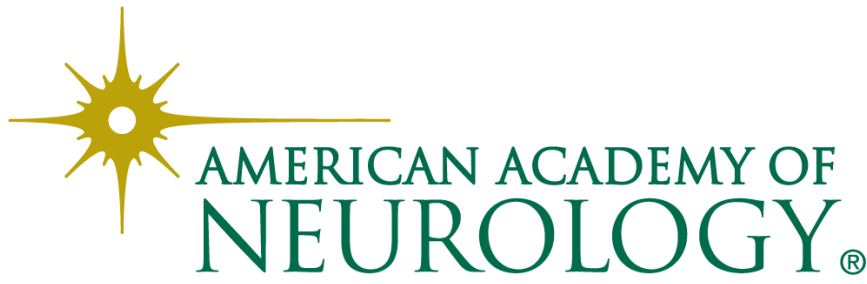

